\title{
Inoculation and colonization of isolated entomopathogenic fungi Beauveria bassiana in rice plants, Oryza sativa L. through seed immersion method
}

\author{
Etr H. K. Khashaba(1)
}

\begin{abstract}
Background: The aims of the present study were to isolate and identify native entomopathogenic fungi, Beauveria bassiana from the Egyptian soil and to evaluate the artificial establishment of B. bassiana as endophytes in rice plants through seeds immersion.

Results: Ten soil samples were collected from different cultivated fields at the Ismailia Governorate. Only one sample was positive with a ratio of $10 \%$. Sequencing of the internal transcribed spacer (ITS) region indicated that the isolate obtained from the soil sample belongs to B. bassiana and was registered under the accession no. MN337282. To test the endophytic colonization of B. bassiana, rice seeds were soaked by $B$. bassiana with a concentration of $5 \times 10^{7}$ spores $/ \mathrm{ml}$, to test when B. bassiana become an endophyte in rice plants. The plants were examined for endophytic presence of B. bassiana, 30 days post treatment. PCR amplification using fungal specific primers for a conserved region of $\beta$-tubulin gene yielded identical $360 \mathrm{bp}$ products from both $B$. bassiana and rice treated plants.
\end{abstract}

Conclusion: The results showed that seeds immersion with a conidial suspension proved to be a good method to introduce $B$. bassiana into rice leaves to protect the rice plants against stem borers.

Keywords: Beauveria bassiana, Endophyte, Rice plants, Isolation, Identification

\section{Background}

Microbial control of insect pests reduces the reliance on chemical pesticides and increases sustainability of agriculture (Singh et al. 2015).

Entomopathogenic fungi (EPF) are an important biological control agent. Beauveria bassiana is a facultative universal entomopathogen with an extremely broad host range. It was first discovered by Agostino Bassi de Lodi in larval of silkworms (Keswani et al. 2013).

$B$. bassiana is considered as the most desired endophytic fungal entomopathogen to date. Endophytes are known to affect the interactions of plants with their

Correspondence: ater_hk@yahoo.com

Plant Protection Research Institute, Agriculture Research Center, Giza, Egypt environment, and to alter the course of their interactions with plant pathogens (Zabalgogeazcoa 2008).

Rice (Oryza sativa L.) is one of the leading food crops in the world and staple for more than half the world's population (Ohtsubo and Sumiko 2007). In Egypt, rice is considered as the second cash-export crop after cotton. There are some constraints to rice production like biotic and abiotic stress that may be overcome by developing new rice varieties. Some of the Egyptian rice varieties are attacked by rice stem borers Chilo agamemnon Bles., which infests rice stems during the vegetative stage, tends to destroy the stems through boring the leaf sheaths at the nodal region, so the use of resistant rice varieties is an economical and efficient method for insects control and for increase crop yield. B. bassiana has 
been used as a biocontrol agent for the coleopteran pests of rice, but there is little knowledge about of its distribution in the rice ecology; therefore, the need to improve our understanding of the ecology of B. bassiana outside and inside the rice plant to allow a wider variety of biological control strategies (Yong et al. 2013).

Several species of entomopathogenic fungi (EPF) occur naturally in different plant species (Vega et al. 2008). Artificial inoculations of plants with conidial suspension of $B$. bassiana have been applied using several methods such as seed soaking, soil drenching, leaf spraying, stem injection, and ridicule inoculation (Russo et al. 2018). Fungal endophytes are commonly defined as fungi that colonize the internal tissues of plants for some or all of their life cycle without causing visible signs of infection (Wilson 1995). Plant colonization by fungal endophytes can either be localized or systemic (Yan et al. 2015). It is confirmed that fungal endophytes can significantly improve host plant tolerance to drought, insects, diseases, and nematodes and act as promoters of plant growth through the increasing of root length, dry and wet weights, crop yield, and even the nutritional status (Greenfield et al. 2016).

The objective of the present investigation was to isolate and identify entomopathogenic fungus, $B$. bassiana from the Egyptian soil samples and to examine the seed inoculation methodology to establish $B$. bassiana as an endophyte in rice seedlings for further introducing a new variety of rice to be used in biological control program.

\section{Methods}

\section{Sampling sites and collection of soil samples}

Ten soil samples were collected from 2 different cultivated orchards with tomato, cabbage in Ismailia Governorate (Lat.: $30^{\circ} 31^{\prime} 57.28^{\prime \prime} \mathrm{N}$, long.: $31^{\circ} 49^{\prime} 12.55^{\prime \prime} \mathrm{E}$ ) during 2019. Within the given site, approximately 3 soil samples of $250 \mathrm{~g}$ each were taken and placed in polyethylene bags, sealed with an adhesive tape and transported to the laboratory.

Soil samples were processed using "Galleria baits method" (Zimmermann 1986). Approximately 240 g soil, dampened with distilled water was placed in $250 \mathrm{~g}$ plastic container and 5 last instar larvae of Galleria mellonella (L.) were placed on the soil. Soil samples were checked every 3 days and dead larvae were removed. Then, they were placed on damp filter paper within a sterile petri dish and incubated at $26 \pm 2{ }^{\circ} \mathrm{C}$ for $7-14$ days (De La Rosa et al. 2000). After the incubation period, fungi were isolated from larvae showing external mycelial growth on Sabouraud dextrose agar medium with $1 \%$ yeast extract (SDAY) in addition to $50 \mu \mathrm{g} / \mathrm{ml}$ chloramphenicol and $50 \mu \mathrm{g} / \mathrm{ml}$ streptomycin (Meyling and Eilenberg 2007).

\section{Molecular identification of Beauveria bassiana}

Ribosomal regions were amplified by PCR from the extracted genomic DNA with some modification (Liu et al. 2000). Polymerase chain reactions (PCR) for the ITS rDNA region using forward primer TW81 (5-GTTTCC GTA GGT GAA CCT GC-3) and reverse primer AB28 (5-ATA TGC TTA AGT TCA GCG GGT-3) (Joyce et al. 1994) were used.

PCR reaction mixture consisted of $1 \mu \mathrm{l}$ of DNA (50 $\mathrm{ng} / \mu \mathrm{l}), 10 \mu \mathrm{l}$ of Master mix BioMix ${ }^{\text {ni }}$ (Bioline), and $1 \mu \mathrm{l}$ $(25 \mathrm{pM})$ each of the forward and reverse primers and made up to a final volume of $20 \mu \mathrm{l}$ with sterile double distilled water. PCR conditions included initial denaturation at $94{ }^{\circ} \mathrm{C}$ for $5 \mathrm{~min}$, followed by 35 cycles of $94{ }^{\circ} \mathrm{C}$ for $45 \mathrm{~s}$., $55^{\circ} \mathrm{C}$ for $1 \mathrm{~min}$, and $72{ }^{\circ} \mathrm{C}$ for $1 \mathrm{~min}$, followed by a final extension at $72{ }^{\circ} \mathrm{C}$ for $5 \mathrm{~min}$. The products were analyzed on $1.2 \%$ agarose gels with TAE buffer.

The PCR products were purified using Wizard ${ }^{\circ}$ SV Gel and PCR clean-Up system Kit (Promega) following the manufacturer's instructions. PCR products were sequenced in both directions by the Macrogen Inc. service, South Korea. The data obtained were evaluated with Finch TV (Blast) programs. The identity of approximately 532 bp sequence was confirmed by a BLAST (Basic Local Alignment Search Tool) search at NCBI and the obtained sequences were submitted and located at the NCBI database with the accession number.

\section{The endophytism of $B$. bassiana in rice plants by seed inoculation}

Two hundred rice seeds were surface sterilized by immersion in 70\% ethanol for $1 \mathrm{~min}$ with constant shaking, then $15 \mathrm{~min}$ in $2 \%$ sodium hypochlorite $(\mathrm{NaOCl})$, followed by 3 washes in sterile water; seeds were then soaked for $24 \mathrm{~h}$ in sterile distilled water. Spore concentrations of fungus were zero (control), and $5 \times 10^{7}$ spores $/ \mathrm{ml}$ with $0.01 \%$ sterile aqueous Triton X-100 (treatment) based on inoculum concentrations used in previous studies of endophytic entomopathogens (Gurulingappa et al. 2010). The beakers containing the soaked seeds and the fungal concentration were placed in a dark environment chamber at $28{ }^{\circ} \mathrm{C}$ until the next day for planting. For the control, rice seeds were immersed with sterile water. Soaked seeds were planted in individual pots $(15 \mathrm{~cm}$ diameter $)$ containing sterilized soil consisting of peat moss, vermiculite, and clay. All plants were grown in a greenhouse at 25 ${ }^{\circ} \mathrm{C}$ with natural photoperiod for the duration of the experiment. Pots were placed in a completely randomized design, watered as needed, and no fertilizer was applied throughout the experiments.

Evaluation for endophytic presence of $B$. bassiana in rice Diagnostic PCR analysis was applied to confirm the presence of the target endophytes in 50 experimental 
plants in the greenhouse experiments after 30 days; DNA was extracted from $B$. bassiana, B. bassiana-treated rice plants and untreated rice plants (negative control) utilizing the CTAB protocol (Rogers and Bendich 1985). Primers for ITS rDNA region were designed as follows: forward primer TW81 (5-GTTTCC GTA GGT GAA CCT GC-3) and reverse primer AB28 (5-ATA TGC TTA AGT TCAG CG GGT-3) (Joyce et al. 1994) and conserved region of fungal $\beta$-tubulin gene (360bp) (Bt2a-fwd: 5 '-GTAACCAA ATCGGTGCTGCTTTC-3' and Bt2b-rev: 5'-ACCC TCAGTGTAGTGACCCTTGGC-3') (Glass and Donaldson 1995) were used.

PCR reaction was set up in a total volume of $20 \mu \mathrm{l}$. The reaction mixture consisted of $1 \mu \mathrm{l}$ of DNA (50 ng/ $\mu \mathrm{l}), 10 \mu \mathrm{l}$ of Master mix BioMix ${ }^{\mathrm{mat}}$ (Bioline), and $1 \mu \mathrm{l}(20$ $\mathrm{pM}$ ) each of the forward and reverse primers and filled to a final volume of $20 \mu \mathrm{l}$ with sterile double distilled water.

The PCR program for ITs primers was set as described above and for $\beta$-tubulin gene as follows: an initial cycle of $94{ }^{\circ} \mathrm{C}$ for $4 \mathrm{~min}$, followed by 30 cycles at $94{ }^{\circ} \mathrm{C}$ for 30 s, $55{ }^{\circ} \mathrm{C}$ for $1 \mathrm{~min}$, and $72{ }^{\circ} \mathrm{C}$ for $30 \mathrm{~s}$, followed by a final extension at $72{ }^{\circ} \mathrm{C}$ for $2 \mathrm{~min}$. PCR products were visualized on a $2 \%$ agarose gel to determine the presence of the inoculated fungal endophytes based on amplification of a DNA fragment of the expected size (positive control). PCR products were then sequenced in both directions using the same primers as used for the initial PCR reactions. The sequences were compared to the entries in GenBank database using BLASTn program.

\section{Detection of $B$. bassiana by light micrograph in treated rice leaves}

It was intended to carry out a comparative microscopically analysis on plant materials which showed the most prominent response of the investigated treatment.

Specimens were killed and fixed at least for $48 \mathrm{~h}$ in FAA $(10 \mathrm{ml}$ formalin, $5 \mathrm{ml}$ glacial acetic acid, $50 \mathrm{ml}$ ethyl alcohol $95 \%$, and $35 \mathrm{ml}$ distilled water). The specimen was washed in $50 \%$ ethyl alcohol, dehydrate in normal butyl alcohol series, embedded in paraffin wax of melting point $56{ }^{\circ} \mathrm{C}$, sectioned to a thickness of $20 \mu \mathrm{m}$, double stained with crystal violet/erythrosine combination, cleared in xylem, and mounted in Canada balsam (Nassar and El-Sahhar 1998). Sections were microscopically analyzed and photomicrographed.

\section{Results}

Out of 10 soil samples collected from different regions at Ismailia Governorate, only one sample was positive to EPN from a field cultivated with tomato with a ratio of $10 \%$. From phenotypic appearance of the mummified G. mellonella after death, and became entirely covered with white mycelia after exposure to high humidity, so defined as $B$. bassiana fungus. Based on the molecular characterization, the ITS region was amplified, sequenced, and the isolate was confirmed to be B. bassiana as the phenotypic identification. The sequence was deposited in the NCBI GenBank database with the accession number (MN337282). The phylogenetic tree was made for the isolate with other B. bassiana isolates found in NCBI GenBank (Fig. 1).

\section{Effect of inoculation method on colonization of $B$. bassiana as endophytes in rice}

Spore germination of $B$. bassiana isolate used to inoculate the rice seed was $>90 \%$. The usage of seed immersion technique successfully introduced the $B$. bassiana isolate into rice plants with a ratio $\sim 70 \%$ of the treated plants after 30 days of greenhouse trial. Also the fungal isolate was successfully recovered from the stem and leaves of rice plants, which clearly indicated that rice, can serve as a good host for B. bassiana endophyte. No growth of EPN was observed in the non-inoculated controls. The plant colonization by $B$. bassiana isolate was determined by the detection of the fungus following the inoculation process through PCR amplification of the ITs sequence producing a single PCR product of 750 bp (Fig. 2).

\section{PCR amplification using primers specific for fungal $\beta$ - tubulin gene}

The PCR using $\beta$-tubulin gene primers amplified a 360 bp product in B. bassiana and in B. bassiana-treated rice plants, but not in untreated rice (Fig. 3). Furthermore, the alignment of $\beta$-tubulin PCR sequences from $B$. bassiana and B. bassiana-treated rice plants was almost identical in sequence as shown in (Fig. 4). Also, the amplified 360 bp sequence showed $99 \%$ similarity with the $\beta$ tubulin-like (TUB2) gene of $B$. bassiana strain isolate A2B (Amatuzzi et al. 2018).

\section{Colonization of $B$. bassiana in the rice tissue}

The presence of $B$. bassiana as an endophyte was detected by a cross-section of the cell wall concerning the penetration hole through the rice tissues entering through the radicle and emerging through the leaves. Figure 5 showed that the infection of B. bassiana was focusing on the phloem for extracting nutrients produced. The epidermal cell wall penetration showed that the plant cell wall was completely punctured and some hyphae were detected growing through the xylem vessels (Fig. 5). No emergence was observed of B. bassiana on the surface of rice leaves or stems.

\section{Discussion}

B. bassiana is found to be one of the common residents of the soil. In this study, it was detected using the 


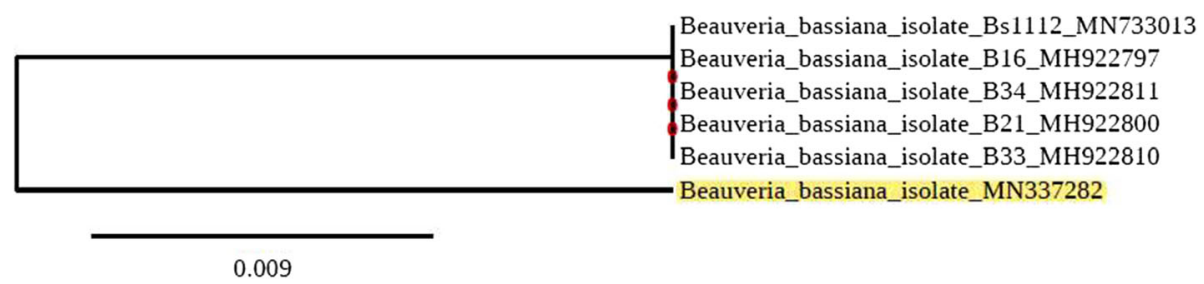

Fig. 1 Maximum likelihood ITS phylogenetic trees of Beauveria bassiana species using ITS sequence. Based on nucleotide sequences of isolated Beauveria bassiana (highlighted) and reference strains with their accession no.(alignment length approximately 532 bp using phylo_tree analysis (Phylogeny.fr. program))

Galleria bait method as described by (Uztan et al. 2016), a good tool for isolation of EPF from soil as reported by Tuininga et al. (2009). Dead Galleria individuals from the positive soil sample from tomato field were pink in color and became entirely covered with white mycelia when exposed to humidity as reported by Humber (1997).

Molecular identification is more important in solving taxonomy problems and to identify fungi at the species level correctly than morphological identification which has many difficulties (Uztan et al. 2016). Usage of ITs for the molecular identification of fungi confirmed the phenotypic identification. This was reported by Uztan et al. (2016). ITS region of rDNA has been considered as a barcode for molecular identification and phylogenetic studies for most of the fungi. Sequence data sets were cleared up and deposited in databases GenBank under accession number MN337282. Studying genetic homogeneity among $B$. bassiana isolates from NCBI database showed similar genetic distances of the isolated $B$. bassiana and other isolates from China and Costa Rica with accession no. MN733013 and MH922811. This agree with the data obtained by Sayed et al. (2018) who mentioned that the isolated samples showed similar genetic distances to the other isolates of Uzbekistan and Chinese isolates.

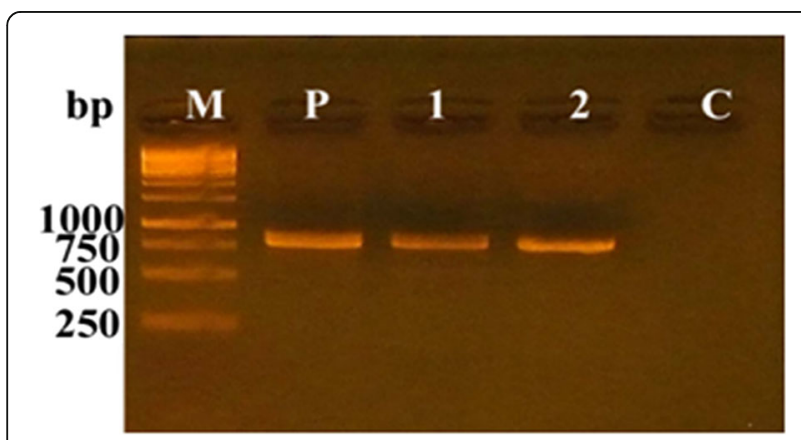

Fig. 2 PCR products amplified of ITS genes from DNA of P: Beauveria bassiana, 1, 2: rice treated with B. bassiana, C: non treated rice, and M: 1 Kbp DNA ladder
Parsa et al. (2013) reported that crop species/cultivar selected, the fungal entomopathogen species strain used and the concentration of the inoculum, the age of the plant during inoculations, the plant's growing conditions, and the plant treatments were factors that could influence the establishment of EPF as an endophyte. As reported in earlier studies, B. bassiana was considered as the most presumed endophytic EPF at present (Singh et al. 2015). Wherefore, the present study demonstrated that seed immersion method was more effective with the usage of fungal strain B. bassiana. This finding disagreed with Saragih et al. (2019) who observed that the seed immersion method gave the lowest percentage of colonization in leaf and stem, while gave the highest percentage of colonization in the root of wheat isolate. The application of $B$. bassiana using seed treatment method would colonize rice plant better in sterile soil than in non-sterile soils which agreed with Bamisile et al. (2018).

As reported by Biswas et al. (2011), endophyte's detection methods based on media cultures are subject to false positives and false negatives. So, the development of more functional detection and quantification methods, like (PCR) assays, is well justified. PCR amplifications with ITS primers of gDNA obtained from $B$.

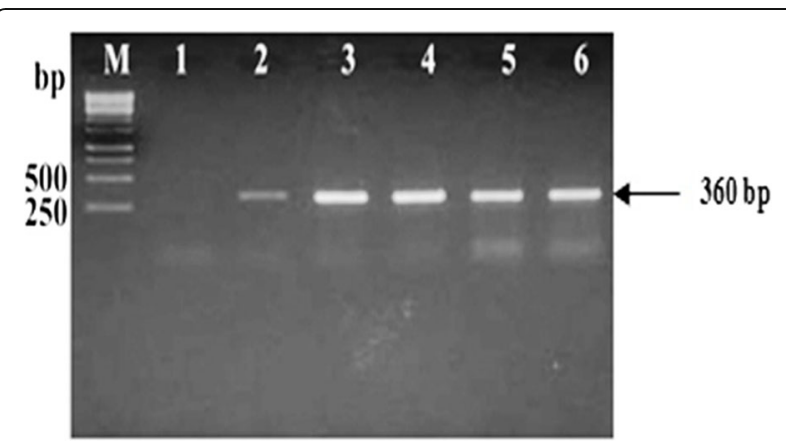

Fig. 3 PCR products amplified using primers specific for a conserved region of the fungal $\beta$-tubulin gene. M: 1 Kbp DNA ladder, 1: untreated rice, 2: Beauveria bassiana, 3-6: rice samples treated with B. bassiana 


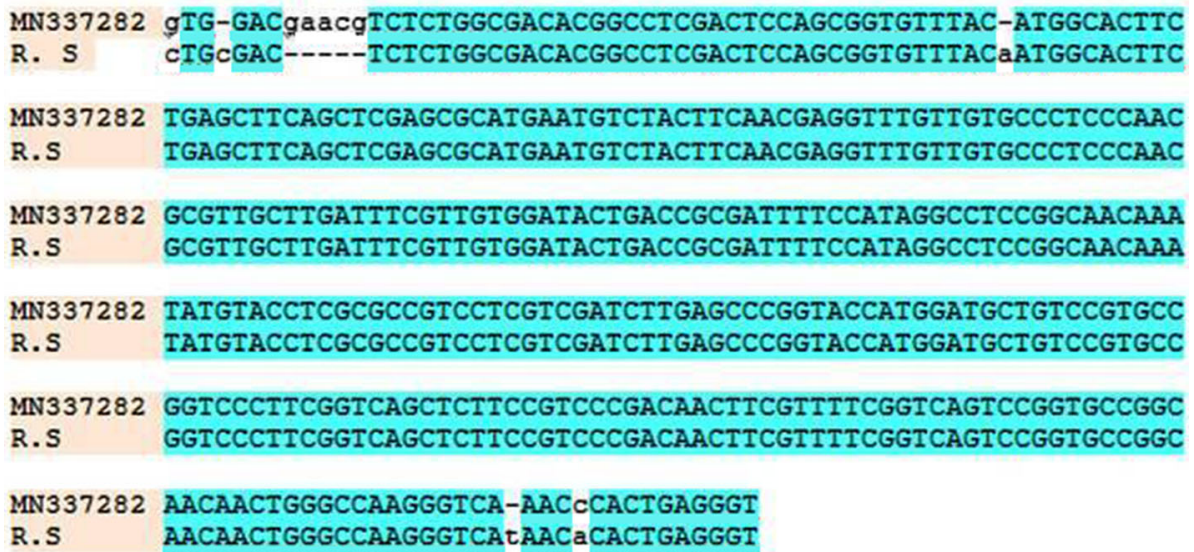

Fig. 4 Alignment of $\beta$ - tubulin gene sequences from Beauveria bassiana and in B. bassiana treated rice plant. Identical positions are shadowed

bassiana and from surface-sterilized B. bassiana-treated rice plants produced large single PCR products of $\sim 750$ bp and were BLASTed showing 100\% similarity. This agree with Quesada-Moraga et al. (2006) as amplified $750 \mathrm{bp}$ PCR products isolated from surface-sterilized opium poppy seeds or seedlings and were BLASTed revealing that the $B$. bassiana and opium poppy sequences shared $100 \%$ similarity with 2 reported ITS1-5.8S-ITS2 sequences. $\beta$-tubulin gene was used to amplify DNA from rice treated plants for the examination of endophytic appearance giving positive results. Moreover, the PCR products from $B$. bassiana and rice treated with the fungi were identical in sequence alignments, so it is concluded that the $B$. bassiana isolate found endophytically in rice plants is the one established through artificial inoculation. These findings agreed with Reddy et al. (2009) when using a similar molecular technique, and reported that using fungal-specific $\beta$-tubulin gene primers gave positive results in $B$. bassiana and sorghum treated with $B$. bassiana and they were identical in sequences. While these results disagreed with Ownley et al. (2008) as assigned their failure to detect $B$. bassiana in B. bassiana-treated tomato seedlings, even though it was endophytically present due to the use of universal primers rather than fungal specific primers.

Many endophytes locally infect plant parts, being restricted to a small tissue area. Some endophytes may be found in specific plant parts such as roots, leaves, or twigs, while others may infect several of these parts (Stone et al. 2004).

Light micrograph was used to detect the colonization of $B$. bassiana in rice tissues and indicated the distortion of the plant cell cuticle caused by the hyphae of $B$. bassiana focusing on the phloem of the rice plants and the

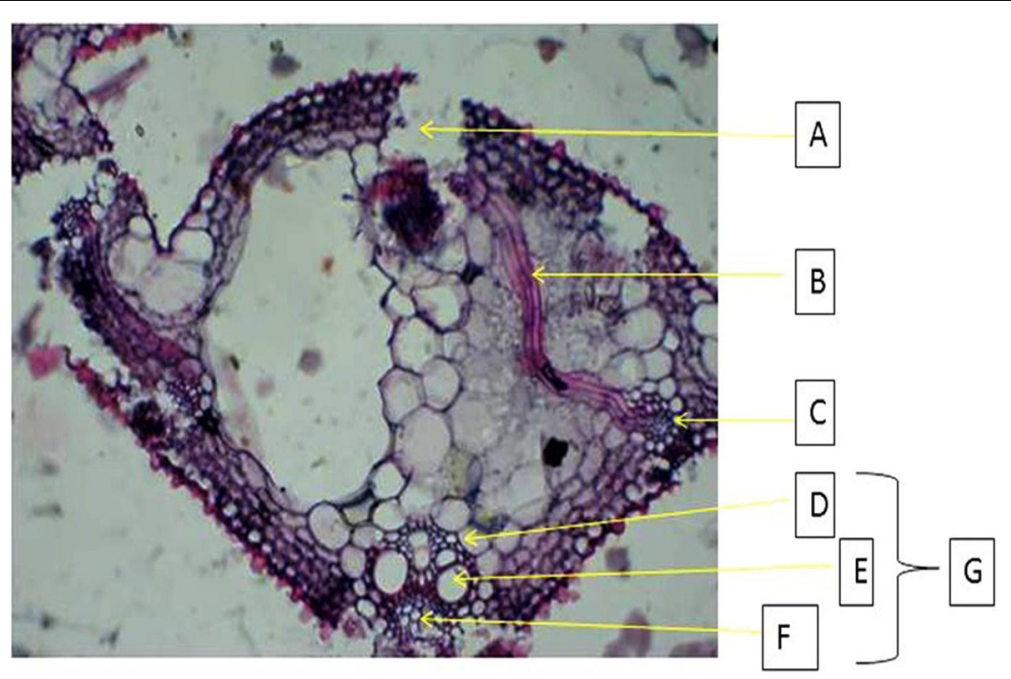

Fig. 5 Light micrograph of cross section of rice leaf epidermal cells showing penetration by Beauveria bassiana. A Destroyed Epidermis was affected by fungi penetration, B Infection hyphae of fungi, C Infected phloem, D Bundle sheath, E Xylem, F Phloem, and G Vascular bundle 
penetration occurred from small hole, which agree with the findings of Quesada-Moraga et al. (2006). They observed the endophytic B. bassiana as relatively short hyphal growth followed by cuticle penetration from a hole to the parenchyma cells and sometimes found in the xylem vessels which could enable the fungus to move within the plant, and provide overall insecticidal protection.

Furthermore, some investigations should be undertaken on the response of the long term establishment throughout the entire life of the inoculated plants. A study of the inheritance of B. bassiana in the next generation on the seeds from infected plants and the virulence of the endophytic fungus in rice against rice stem borers is needed.

\section{Conclusion}

The present study demonstrated that $B$. bassiana can be established as an endophyte in rice plants without an opposite effect on plant growth, and stated that seed inoculation with a conidial suspension proved to be an effective method to introduce $B$. bassiana into rice plants.

\section{Abbreviations}

ITS: Internal transcribed spacer; B. bassiana: Beauveria bassiana; $\beta$ tubulin: Beta-tubulin

\section{Acknowledgements}

We would like to thank Prof. Dr. Gamal A. El Kady (Department of plant protecion, Faculty of Agriculture, Suez Canal University), Prof. Dr. Reda E. Moghaieb (Department of Genetics, Faculty of Agriculture, Cairo University) for helping in the critical reading of the manuscript. And Dr. Ahmed Eisa Ghoniem (Department of botany, Faculty of Agriculture, Cairo University) for helping in Light micrograph analysis.

\section{Author's contributions}

E.H.K.K. design the experiments and practical work and manuscript writing. The author(s) read and approved the final manuscript.

\section{Funding}

Not applicable.

\section{Availability of data and materials}

All datasets are presented in the main manuscript.

\section{Declarations}

Ethics approval and consent to participate

Not applicable.

\section{Consent for publication}

Not applicable.

\section{Competing interests}

The authors declare that they have no competing interests.

Received: 23 February 2021 Accepted: 10 May 2021

Published online: 12 June 2021

\section{References}

Amatuzzi RF, Poitevin CG, Poltronieri AS, Zawadneak MAC, Pimentel IC (2018)

Entomopathogenic fungi as a biological control agent against Duponchelia fovealis Zeller (Lepidoptera: Crambidae). Insects 19:9(2). https://doi.org/10.33 90/insects9020070

Bamisile B, Dash CK, Akutse KS, Ravindran K (2018) Prospects of endophytic fungal entomopathogens as biocontrol and plant growth promoting agents: an insight on how artificial inoculation methods affect endophytic colonization of host plants. Microbiol Res 217:34-50. https://doi.org/10.1016/j. micres.2018.08.016

Biswas C, Dey P, Satpathy S, Satya P (2011) Establishment of the fungal entomopathogen Beauveria bassiana as a season long endophyte in jute (Corchorus olitorius) and its rapid detection using SCAR marker. BioControl 57: $565-571$

De La Rosa W, Segura HR, Barrera JF, Williams T (2000) Laboratory evaluation of the impact of entomopathogenic fungi on Prorops Nasuta (Hymenoptera: Bethylidae), a parasitoid of the coffee berry borer. Environ Entomol 29:126-131

Glass NI, Donaldson GC (1995) Development of primer sets designed for use with the PCR to amplify conserved genes from filamentous ascomycetes. Appl Environ Microbiol 61(4):1323-1330 PMid: 7747954

Greenfield M, Gómez Jiménez Ml, Ortiz V, Vega FE, Kramer M, Parsa S (2016) Beauveria bassiana and Metarhizium anisopliae endophytically colonize cassava roots following soil drench inoculation. Biol Control 95:40-48

Gurulingappa P, Sword GA, Murdoch G, McGee PA (2010) Colonization of crop plants by fungal entomopathogens and their effects on two insect pests when in planta. Biol Control 55:34-41

Humber RA (1997) Fungi: identification. In: Lacey LA (ed) Manual of techniques in insect pathology. Academic, London, pp 153-185 J Funct Foods 5(2): 689-697.

Joyce SA, Burnell AM, Powers TO (1994) Characterization of Heterorhabditis isolates by PCR amplification of segments of mtDNA and rDNA genes. J Nematol 26:260-270

Keswani C, Singh SP, Singh HB (2013) Beauveria bassiana: status, mode of action, applications and safety issues. ljor 3(1):16-20

Liu D, Coloe S, Baird R, Pedersen J (2000) Rapid mini-preparation of fungal DNA for PCR. J Clin Microbiol 1:471

Meyling NV, Eilenberg J (2007) Methods for isolation of entomopathogenic fungi from the soil environment. Lab Manual 32:818-890 http://orgprints.org/11200

Nassar MA, El-Sahhar KF (1998) Botanical preparation and microscopy (Microtechniques). Academic Bookshop, Dokki, p 219

Ohtsubo K, Sumiko N (2007) Cultivar identification of rice (Oryza Sativa L.) by polymerase chain reaction method and its application to processed rice products. J Agric Food Chem 55(4):1501-1509

Ownley BH, Griffin MR, Klingeman WE, Gwinn KD, Moulton JK, Pereira RM (2008) Endophytic colonization and plant disease control. J Inverte Pathol 98:267-270

Parsa S, Ortiz V, Vega FE (2013) Establishing fungal entomopathogens as endophytes: towards endophytic biological control. J Vis Exp 74(50360):1-5

Quesada-Moraga E, Landa BB, Munoz-Ledesma J, Jimenez-Diaz RM, SantiagoAlvarez C (2006) Endophytic colonization of opium poppy Papaver somniferum by an entomopathogenic Beauveria bassiana strain. Mycopathology 161:323-329

Reddy NP, Akbar PA, Devi UK, Sharma HC, Reineke A (2009) Treatment of millet crop plant (Sorghum bicolor) with the entomopathogenic fungus (Beauveria bassiana) to combat infestation by the stem borer, Chilo partellus Swinhoe (Lepidoptera: Pyralidae). J Asia Pac Entomol 12:221-226

Rogers SO, Bendich AJ (1985) Extraction of DNA from milligram amounts of fresh, herbarium and mummified plant tissues. Plant Mol Biol 5:69-76

Russo ML, Pelizza SA, Vianna MF, Allegrucci N, Cabello MN, Toledo AV, Mourelos C, Scorsetti AC (2018) Effect of endophytic entomopathogenic fungi on soybean Glycine max (L.) Merr. growth and yield. J King Saud Univ Sci 31(4): 728-36. https://doi.org/10.1016/j.jksus.2018.04.008

Saragih M, Nurbailis T, Yusniwati (2019) Entomopathogenic fungus, Beauveria bassiana to red chili (Capsicum annuum L.) with different inoculation methods. In: The 4th Inter Confer on Biolo Sci Biotchnol IOP Conf. Series: Earth and Environmental Science IOP Conf. 305. https://doi.org/10.1088/1 755-1315/305/1/012070

Sayed SM, Ali EF, El-Arnaouty SA, Mahmoud SF, Amer SA (2018) Isolation identification, and molecular diversity of indigenous isolates of Beauveria bassiana from Taif region, Saudi Arabia. Egypt J Biol Pest Control 28:47

Singh HB, Keswani C, Ray S, Yadav SK, Singh SP, Singh S, Sarma BK (2015) Beauveria bassiana: biocontrol beyond lepidopteran pests. Springer International Publishing Switzerland K.S. Sree, A. Varma (eds.). Biocontrol 
Lepidopteran Pests, Soil Biol 43. https://doi.org/10.1007/978-3-319-144 99-3_10

Stone JK, Polishook JD, White JF (2004) Endophytic fungi. In: Mueller GM, Bills GF, Foster MS (eds) Biodiversity of fungi. Inventory and monitoring methods. Elsevier Acad Press, San Diego, pp 241-270

Tuininga AR, Miller JL, Morath SU, Daniels TJ, Falco RC, Marchese M, Sahabi S, Rosa D, Stafford KC (2009) Isolation of entomopathogenic fungi from soils and Ixodes scapularis (Acari: Ixodidae) ticks: prevalence and methods. J Med Entomol 46(3):557-565

Uztan AH, Gunyar OA, Yoltas A, Keskin N (2016) Isolation and identification of entomopathogenic fungi Beauveria bassiana from Turkey. Fresenius Environ Bull 25(12):5180-5185

Vega FE, Posada F, Aime MC, Pava-Ripolli M, Infante F, Rehner SA (2008) Entomopathogenic fungal endophytes. Biol Control 46:72-82

Wilson D (1995) Endophyte- the evolution of a term, and clarification of its use and definition. Oikos 73:274-276

Yan JF, Broughton SJ, Yang SL, Gange AC (2015) Do endophytic fungi grow through their hosts systemically? Fungal Ecol 13:53-59

Yong J, Zhou J, He J, Du W, Bu Y, Liu C, Dai C (2013) Distribution of the entomopathogenic fungus Beauveria bassiana in rice ecosystems and its effect on soil enzymes. Curr Microbiol 67:631-636

Zabalgogeazcoa I (2008) Review. Fungal endophytes and their interaction with plant pathogens. Span J Agric Res 6:138-146

Zimmermann G (1986) The 'Galleria bait method' for detection of entomopathogenic fungi in soil. J Appl Entomol 102:213-215

\section{Publisher's Note}

Springer Nature remains neutral with regard to jurisdictional claims in published maps and institutional affiliations.

\section{Submit your manuscript to a SpringerOpen ${ }^{\circ}$ journal and benefit from:}

- Convenient online submission

- Rigorous peer review

- Open access: articles freely available online

- High visibility within the field

- Retaining the copyright to your article

Submit your next manuscript at $\boldsymbol{\triangleright}$ springeropen.com 